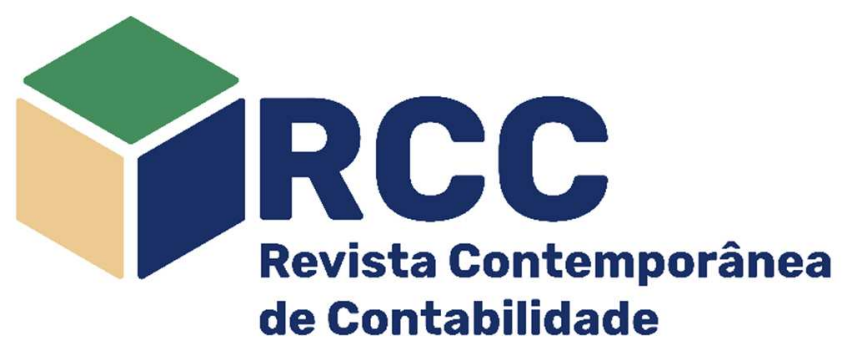

\title{
Red flags de auditoria e divulgação das deficiências de controles internos nas empresas do IBRX 100
}

\author{
Audit red flags and internal control weaknesses disclosure in IBRX 100 listed companies

\begin{abstract}
Las red flags de auditoría y la divulgación de las deficiencias de control interno en empresas del IBRX 100
\end{abstract}

\author{
Carolini Verdan Brandão \\ Mestranda em Ciências Contábeis (UFES), \\ Vitória/ES, Brasil \\ caroliniverdan@hotmail.com \\ https://orcid.org/0000-0002-6745-8564 () \\ Vagner Antônio Marques \\ Doutor em Administração (UFMG) \\ Professor e Coordenador do Programa de Pós-graduação \\ em Ciências Contábeis (UFES), Vitória/ES, Brasil \\ vagner.marques@ufes.br \\ https://orcid.org/0000-0001-7210-4552 (0)
}

\author{
Laíse Mascarenhas Ballarini* \\ Mestranda em Ciências Contábeis (UFES), \\ Vitória/ES, Brasil \\ laiseballarini@gmail.com \\ https://orcid.org/0000-0002-3514-9281 (1)
}

\author{
Viviane da Costa Freitag \\ Doutora em Contabilidade (UNISINOS) \\ Professora do Departamento de Finanças e Contabilidade (UFPB), \\ João Pessoa/PB, Brasil \\ viviane.freitag@academico.ufpb.br \\ https://orcid.org/0000-0001-8989-1361 (i)
}

Endereço do contato principal para correspondência* Av. Fernando Ferrari, 514 - Centro de Ciências Jurídicas e Ecconômicas, CEP: 29.075-910 - Vitória/ES, Brasil

\begin{abstract}
Resumo
Este estudo analisou o efeito das Red Flags de Auditoria (RFA) sobre a divulgação de Deficiências de Controles Internos (DCI) das empresas participantes do Índice Brasil 100 da B3, no período de 2010 a 2018. A pesquisa, de natureza descritiva, documental e com abordagem quantitativa, utilizou-se da análise de conteúdo, testes de diferenças entre as médias/medianas/proporções e análise de regressão, logística e de Poisson para a análise dos dados. Os resultados evidenciaram que as categorias de $\mathrm{DCl}$ mais divulgadas foram: Políticas Contábeis; Falhas Tecnológicas; e Contas Específicas. As RFA relacionadas às vendas, contas a receber e depreciação, reduzem a probabilidade de divulgação de uma $\mathrm{DCl}$, enquanto aquelas relacionadas à lucratividade e endividamento, aumentam. Os resultados reforçam o papel das RFA como sinalizadores de problemas nos controles internos das empresas, contribuindo para a avaliação de risco e redução da assimetria informacional para investidores, auditores, reguladores e demais usuários da informação contábil.
\end{abstract}

Palavras-chave: Deficiências de Controles Internos; Red Flags; Risco de Auditoria

\section{Abstract}

This study analyzes the effect of Audit Red Flags (ARF) on the Internal Control Weaknesses (ICW) of IBRX 100 (Brazil100 Index) listed companies from 2010 to 2018. Data were analyzed using content analysis, average/median/proportion differences test, and logistic/Poisson regression. Results showed the types of ICW most disclosured were accounting policy; technology failures; and specific accounts. It was also observed that red flags related to revenues, receivable account, and depreciation reduce the probability of ICW disclosure, while those related with profitability and debt increase it. The findings are consistent for different specifications and increase the ARF role as flags of ICW contributing for risk assessment and decrease of informational asymmetry of investors, auditors, regulators, and accounting information users.

Keywords: Weaknesses of Internal Control; Red Flags; Auditing Risk

\section{Resumen}

Este estudio analizó el efecto de las Red Flags de Auditoría (RFA) en la divulgación de las Deficiencias de Controles Internos (DCl) de las empresas participantes del índice Brasil 100 de la B3 en el período de 2010 a 2018. Para el análisis de los datos se utilizaron análisis de contenido, pruebas de diferencias entre 
medias/medianas/proporciones y regresión, análisis logístico y de Poisson. Los resultados mostraron las categorías de DCI más publicados: Políticas contables; Fallos tecnológicos; y Cuentas específicas. Las RFA relacionadas con las ventas, las cuentas por cobrar y la depreciación reducen la probabilidad de revelar un $\mathrm{DCl}$, mientras que las relacionadas con la rentabilidad y el endeudamiento aumentan. Los resultados refuerzan el papel de las RFA como señal de problemas en los controles internos, contribuyendo a la evaluación de riesgos y reduciendo la asimetría de información para inversores, auditores, reguladores y otros usuarios de la información contable.

Palabras clave: Deficiencias de los controles internos; Red Flags; Riesgo de auditoría

\section{Introdução}

O estudo buscou analisar o efeito das Red Flags de Auditoria (RFA) sobre a divulgação de Deficiências de Controles Internos (DCl) das empresas de capital aberto que compõem o Índice Brasil 100 (IBRX 100), listadas na Brasil, Bolsa e Balcão B3. As Red Flags de Auditoria (RFA) ou bandeiras vermelhas representam sinais de alerta utilizados pelo auditor a fim de avaliar o risco de auditoria, em especial, a probabilidade de ocorrência de erro material ou fraudes nas demonstrações contábeis da entidade (Gullkvist \& Jokipii, 2013). Sua ocorrência não significa que a empresa cometeu um ato ilícito, fraudulento ou que tenha incorrido em erro material, mas alerta o auditor para se atentar a determinados fatores apontados como associados ao risco de fraude e/ou erro materiais (Cao, Luo \& Zhang, 2019).

Visando identificar o nível de risco associado a cada trabalho, os auditores utilizam as RFA e classificam a estrutura de controle interno com o intuito de avaliarem os níveis de risco de erro ou fraude (Donelson, Ege \& Mcinnis, 2017; Baader \& Krcmar, 2018). Segundo Rae, Sands e Subramaniam (2017), os controles internos podem ser definidos como o conjunto de processos, métodos e técnicas utilizados para a adequada execução das atividades e utilização de recursos com vistas à eficácia e à eficiência das operações, bem como à confiabilidade das demonstrações financeiras e conformidade com leis e regulamentos aplicáveis à empresa.

Desde 2010, a partir da Resolução do Conselho Federal de Contabilidade CFC 1.210/2009, que aprovou a Norma Brasileira de Contabilidade NBC TA 265 - Comunicação de Deficiências de Controle Interno, o auditor passou a ser responsável por comunicar aos administradores da companhia a ocorrência de $\mathrm{DCl}$ ao longo do processo de asseguração das demonstrações contábeis. Segundo a Comissão de Valores Mobiliários (2016), a inexistência de DCl é uma situação excepcional, e ainda que esta não se apresente, o auditor deverá registrar a não detecção em seu relatório. Segundo Ge e McVay (2005) e Ge, Koester e McVay (2017), a divulgação das fragilidades dos controles internos pelas entidades potencializa a avaliação dos riscos de ocorrência de erros e/ou fraudes contábeis nas demonstrações financeiras.

Ge e McVay (2005) evidenciaram que setores mais complexos tendem a apresentar maiores fragilidades nos controles internos. Por outro lado, empresas mais rentáveis e com maior quantidade de recursos tenderam a reportar menos DCI. Lenard, Petruska, Alam e Yu (2016) destacam que existe uma associação positiva entre as fragilidades dos controles internos e a manipulação das operações reais das empresas, logo, tal divulgação funciona como mecanismo de monitoramento dos agentes e da avaliação do risco de maior assimetria informacional.

Donelson et al. (2017) destacaram que controles internos falhos aumentam a ocorrência e a extensão das fraudes nos relatórios financeiros por altos executivos. Segundo os autores, os controles internos deficientes estão relacionados a um maior risco de fraude contábil não revelada, sendo assim, controles internos insuficientes podem aumentar o risco de fraude e incentivar os gerentes a praticarem atos ilícitos. Complementarmente, a NBC TA 265 - Comunicação de Deficiências de Controles Internos afirma, no item A5, que uma deficiência significativa no controle interno "não depende somente se a distorção realmente ocorreu, mas, também, da probabilidade de que a distorção poderia ocorrer e a possível magnitude da distorção", e exemplifica, em seu item A6, "a susceptibilidade à perda ou à fraude do respectivo ativo ou passivo", que pode ser entendida como uma red flag, se apresenta como possível indicativo de um potencial sintoma de fraude contábil (CFC, 2009).

Existe uma ampla literatura que discute sobre Deficiências de Controle Interno no contexto internacional: Ge e McVay (2005) identificaram as fragilidades dos controles internos após a implantação da Lei Sarbanes Oxley; Ge et al. (2017) analisaram as formas de evidenciação dos controles internos em pequenas empresas; Lenard et al. (2016) verificaram se há relação entre as $\mathrm{DCl}$ e o nível de manipulação das atividades; Donelson et al. (2017) estudaram a associação entre as DCl e o risco de fraude; e Bauer, Bucaro e Estep (2019) analisaram a associação entre as DCl e a possibilidade de cometer fraude. Outra vertente da literatura explora as red flags de auditoria, tal como nos estudos de Gullkvist e Jokipii (2013), que examinaram a percepção da importância dessas ferramentas em relatórios financeiros; Baader e Krcmar (2018), que identificaram possíveis processos fraudulentos a partir da análise de processos associados à sinalização das red flags; e Cao et al. (2019), que, por sua vez, verificaram se mudanças positivas e negativas anormais no emprego funcionam como potenciais sinalizadores de riscos de distorções vinculados à essas decisões. Todavia, nesses estudos as temáticas foram analisadas 
isoladamente, mesmo havendo evidências de associação entre ambas (Hammersley, Myers \& Shakespeare, 2008).

Na literatura nacional, Teixeira e Cunha $(2016 ; 2016 a)$ desenvolveram dois estudos sobre as DCls: no primeiro investigaram a relação existente entre as $\mathrm{DCl}$ moderadas pelos seus determinantes, enquanto que no segundo propuseram um índice para as DCl. Fiirst, Pamplona, Haag e Silva (2017) identificaram o nível de evidenciação de fatores de risco e o reporte de DCl. Ainda nesse espectro, Lopes, Marques e Louzada (2019) identificaram quais DCls estavam sendo apresentadas. Ressalta-se que, no contexto nacional, também não foram encontrados estudos que analisassem a associação entre $\mathrm{DCl}$ e red flags. Diante disso, a presente pesquisa buscou preencher essa lacuna e responder ao problema: Qual o efeito das red flags de auditoria sobre as deficiências de controle interno nas empresas do IBRX 100 da B3?

A pesquisa de natureza descritiva, documental e com abordagem predominantemente quantitativa, analisou dados do período de 2010 a 2018 das 96 empresas que compunham o Índice Brasil 100 (IBRX 100) em 31/12/2018. Essa amostra foi selecionada, pois segundo Ge e McVay (2005), existe uma tendência de que empresas de grande porte sejam auditadas por grandes empresas e, consequentemente, estas estão sujeitas a uma maior detecção de $\mathrm{DCl}$ por estarem expostas a maiores responsabilidade legal, risco de litígio e reputação.

Assim, o desenvolvimento desta pesquisa se justifica por diversos motivos: o primeiro deles é pela relevância da divulgação das $\mathrm{DCl}$ para a redução da assimetria informacional (Clinton, Pinello \& Skaife, 2014). Segundo, porque a redução da assimetria melhora a avaliação de risco e precificação dos ativos pelos usuários externos (Hammersley et al., 2008). Terceiro, porque tanto as red flags quanto as DCl constituem-se de elementos adicionais utilizados pelos auditores, usuários da informação e reguladores para a avaliação do risco de fraude e erros materiais (Lenard et al., 2016; Donelson et al., 2017; Bauer, et al., 2019). Por fim, o quarto motivo se ampara na escassez de estudos que avaliem a associação entre ambas, em especial no contexto brasileiro, buscando preencher, portanto, uma lacuna existente nos estudos sobre auditoria e contabilidade. Desta forma, o presente estudo tem potencial de contribuição para os administradores, contadores, auditores, investidores, reguladores e demais usuários da informação contábil, pois a evidência empírica das relações existentes entre as $\mathrm{DCl}$ e as RFA apontadas pode aumentar o conteúdo informacional contábil reportado.

Este estudo se divide em 5 seções, a contar com esta introdução. A seção 2 discute a Teoria de Agência e o papel da estrutura de controles internos, a importância das RFA e estudos anteriores. Na seção 3 são apresentados os procedimentos metodológicos. Na seção 4 apresenta-se a análise de dados e resultados e, por fim, a seção 5 apresenta as considerações finais e sugestões para estudos futuros.

\section{Referencial Teórico}

\subsection{Teoria de Agência e o Papel da Estrutura de Controles Internos}

A Teoria da Agência considera que existe um conflito de interesse iminente na relação entre os gestores (agentes) e os acionistas (principais), pois os agentes podem priorizar os seus interesses privados em detrimento aos dos acionistas. Brickley e Zimmerman (2010) reforçam que, a despeito de muitos mitos serem construídos sobre o tema, os "problemas de agências" têm efeito potencial sobre a ocorrência de fraudes e erros, uma vez que os agentes podem reportar informações enviesadas de forma oportunista, potencializando os problemas decorrentes da assimetria informacional e a chance de seleção adversa por parte dos usuários externos.

Nesse contexto, a estrutura de governança funciona como estratégia para mitigação dos problemas de agência, pois, a partir da estrutura de controles internos, conselhos fiscal, de auditoria e outros mecanismos internos ou externos, tais como o pacote de incentivos, busca-se alinhar os interesses das partes reduzindo o risco de expropriação (Rae, Sands \& Subramaniam, 2017). Nesse âmbito, Hoi, Wu e Zhang (2019) evidenciaram que o pacote de incentivos é uma estratégia recorrentemente utilizada para mitigar o conflito de agentes. Liu e Liu (2017), por seu turno, observaram que os incentivos financeiros melhoram a propensão dos gestores em reduzir, entre outros fatores, as Deficiências de Controles Internos (DCl), que, a princípio, funcionam como mecanismos de restrição do comportamento oportunista dos agentes. Bolton, Liam, Rupley e Zhao (2016), por sua vez, destacaram, entretanto, que a divulgação das $\mathrm{DCl}$ tem um efeito coercitivo sobre o comportamento das firmas e entre seus pares, pois consideraram que a divulgação de tais deficiências pode afetar os preços das ações e, além disso, funcionam como mecanismos de monitoramento dos competidores.

$\mathrm{Li}$, Park e Wynn (2018) observaram que os agentes podem selecionar as DCl que serão reportadas, considerando o seu potencial efeito sobre o comportamento dos investidores, o que funcionaria como um incentivo para selecionar e gerenciar a divulgação. No contexto americano, com a vigência da Lei Sarbanes-Oxley (SOX) de 2002, dadas as expectativas de transparência quanto à estrutura de controles internos e o sistema contábil, as empresas de capital aberto passaram a fornecer aos seus acionistas um relatório sobre as deficiências identificadas no controle interno para fins de avaliação e tomada de decisão (Hammersley et al., 2008; Clinton et al., 2014; Li et al., 2016). 
Diante disso, Ge e McVay (2005) levantaram 493 diferentes tipos de deficiências, elencadas de acordo com as exigências da Seção 302 da SOX de 2002. Os autores categorizaram tais deficiências em nove grupos distintos, a saber: Contas Contábeis Específicas; Treinamento de Profissional Contábil; Políticas de Relatórios/Contabilidade em final de período; Reconhecimento de Receita; Segregação de Funções; Reconciliação de Contas; Subsidiária Específica; Gerenciamento Sênior; e Problemas de Tecnologia.

O Brasil seguiu a mesma linha de exigência por meio da criação da NBC TA 265 - Comunicação de Deficiências de Controle Interno. Tal norma exige que o auditor independente divulgue as $\mathrm{DCl}$ em relatório circunstanciado, conforme o seu julgamento profissional. A Comissão de Valores Mobiliários (CVM) ratifica esta exigência por meio da Instrução CVM no 308, art. 25, inciso II (CVM, 1999, p. 10), que determina que o auditor independente deve "elaborar e encaminhar à administração e ao Conselho Fiscal, relatório circunstanciado que contenha suas observações em relação aos controles internos [...] descrevendo, ainda, as eventuais deficiências ou ineficácias identificadas no transcorrer dos trabalhos". Este relatório circunstanciado constava até 2014 no item 10.6.b do Formulário de Referência "Comentários dos diretores" - "deficiências e recomendações sobre os controles internos presentes no relatório do auditor independente" (ICVM № 480, 2009). A partir de 2015, esses relatos passaram a ser reportados no item 5.3.d - "Política de gerenciamento de riscos e controles internos" - do mesmo formulário, tratando dentre outros elementos que se referem ao risco, sobre as $\mathrm{DCl}$, que trata das deficiências e recomendações sobre os controles internos, informando também se a deficiência é ou não significativa, conforme estrutura o Anexo 24 da ICVM no 480 (2009) alterada pela ICVM no 552 (2014).

Ressalta-se que tanto a NBC TA 265 quanto o conjunto de Instruções da CVM que versam sobre a evidenciação de $\mathrm{DCl}$ não especificam quais são as potenciais fragilidades nos controles que as empresas podem enfrentar, uma vez que cada firma pode estar sujeita a fragilidades particulares. Assim, a mudança produzida pela ICVM ํㅡ 552 (2014) não se trata de nova obrigatoriedade, mas apenas incorre em novo posicionamento de informações.

\subsection{A Importância das Red Flags de Auditoria (RFA)}

Gullkvist e Jokipii (2013) afirmaram que as RFA são utilizadas na detecção de risco de fraude e/ou manipulação das demonstrações financeiras. Dado que os auditores (internos e externos) lidam com avaliação de processos complexos e com julgamentos permanentes quanto aos eventos sob sua avaliação, e que tais julgamentos serão sintetizados no relatório de auditoria, a utilização dessas RFA funcionam como uma heurística que simplifica e dá objetividade ao processo de investigação e detecção de fraudes ou erros materiais.

Para Krambia-Kapardis, Christodoulou e Agathocleous (2010), as RFA podem aumentar a percepção dos auditores na detecção de fraudes. Gullkvist e Jokipii (2013) complementaram que as RFA são indicadas pelos reguladores como uma das etapas de combate à fraude, embora pesquisas evidenciem limitações quanto ao seu poder de detecção e previsão.

Hegazy e Kassem (2010) afirmaram que as RFA ajudam os auditores a focarem seu trabalho em fatores críticos já sinalizados, ainda na etapa de planejamento. Os autores observaram que as evidências encontradas até então demonstravam que os erros e fraudes decorrentes da manipulação de receitas (em especial o reconhecimento antecipado), e a ocultação de passivos e despesas, são as preponderantes. Desse modo, RFA relacionadas a esses eventos podem evidenciar sinais de anomalias no processo de auditoria das firmas.

A literatura sobre detecção de fraudes e erros apresenta uma diversidade de red flags qualitativas e quantitativas para a sua identificação, tal como nos estudos de Krambia-Kapardis et al. (2010); Gullkvist e Jokipii (2013); Omar, Johari, Amirah, e Smith (2017); Baader e Krcmar (2018) e Cao et al. (2019). Porém, o trabalho de Beneish (1999) direciona, em alguma medida, boa parte dos principais estudos subsequentes sobre o tema, seja com os argumentos, seja com as métricas utilizadas (Beneish, Lee \& Nichols, 2013). Beneish (1999) analisou oito índices que podem ser utilizados para detectar distorções nas demonstrações contábeis e que potencialmente podem resultar em fraudes. Entretanto, em seu estudo, apenas cinco apresentaram significância estatística.

Grove e Cook (2004) analisaram as empresas Enron, WorldCom, Qwest e Global Crossing e concluíram que os índices que funcionaram como boas red flags quantitativas foram: o Índice de Margem Bruta (IMB) e Índice de Crescimento de Vendas (ICV). Ressalta-se que tais métricas também foram utilizadas por Beneish (1999). Além disso, os autores acrescentaram à análise: Boo-to-Market Price/Earnings; Margem de Lucro; $\triangle$ Receita e $\Delta$ Lucro; Retorno sobre os Ativos (ROA); Retornos sobre o Patrimônio Líquido (ROE); Liquidez Corrente (LC); Índice de Qualidade dos Lucros (IQL) e a Taxa de Imposto Efetiva (TIE). Nesse ínterim, Grove e Basilico (2008) confirmaram que as mesmas red flags financeiras (quantitativas) analisadas em Beneish (1999) foram eficazes para sinalização prévia de fraudes, e os indicadores que receberam destaque no seu estudo foram: Índice de Margem Bruta (IMB); Índice de Crescimento de Vendas (ICV); e Índice de Dias de Vendas em Recebíveis (IDVR). Além dos citados, Grove e Cook (2007), Feroz, Kwon, Pastena e Park (2000) destacaram, ainda, que red flags qualitativas de 
governança corporativa, junto com as quantitativas, auxiliaram os apontamentos de fraudes.

\subsection{O que se Sabe sobre as Deficiências de Controles Internos e Red Flags de Auditoria?}

A discussão sobre os controles internos é considerada um tema emergente nas pesquisas em auditoria e, nos últimos anos, diversos trabalhos publicados na literatura estrangeira têm apresentado evidências sobre as deficiências ou fraquezas materiais nos controles internos e suas implicações sobre processo decisório, qualidade dos lucros, entre outras (Ettredge, Li \& Sun, 2006; Choi, Hogan \& Lee, 2013). Entretanto, o debate sobre o tema no contexto brasileiro ainda é escasso: alguns estudos foram publicados em eventos científicos, enquanto nenhum trabalho foi localizado em periódicos nos estratos superiores do Qualis CAPES (Teixeira \& Cunha, 2016; Teixeira \& Cunha, 2016a; Fiirst et al., 2017; Lopes, Marques \& Louzada, 2019).

Teixeira e Cunha (2016) buscaram analisar a relação existente entre as DCl moderadas pelos seus determinantes. Os resultados evidenciaram que as $\mathrm{DCl}$ possuem efeito moderador significativo sobre: (i) auditoria; (ii) delay em auditoria; (iii) opinião modificada; e (iv) republicação das demonstrações contábeis. Em estudo posterior, Teixeira e Cunha (2016a) propuseram um índice de $\mathrm{DCl}$ das empresas brasileiras a partir das categorias propostas por Ge e McVay (2005). Nele, verificaram que 24,3\% das empresas apresentaram DCl e as relacionadas a TI, Grupos de Demonstrações Contábeis, Geral, Litígios, Contas Específicas, Subsidiárias, e Alta Administração foram as categorias predominantes.

O estudo de Fiirst et al. (2017) buscou identificar o nível de evidenciação de fatores de risco e o reporte de DCl das empresas brasileiras com programas de American Depositary Receipts da Bolsa de Nova lorque. Os riscos identificados na amostra foram: estratégicos; de mercado; de crédito; de liquidez; operacionais; legais; de imagem; e ambientais, sendo que a evidenciação deles não foi considerada homogênea. Os autores demonstraram que empresas com divulgação de $\mathrm{DCl}$ possuem uma maior evidenciação de risco em imagem.

Já Lopes, Marques e Louzada (2019) analisaram dados de 32 empresas listadas na Bolsa, Brasil e Balcão B3, no período de 2010-2015, e constataram que $87 \%$ das deficiências reportadas com informações suficientes para categorizá-las referiram-se a: (i) Treinamento - 23\%; (ii) Falhas Tecnológicas - 20\%; (iii) Falhas em Subsidiárias - 17\%; (iv) Contas Específicas - 15\%; e (v) Segregação de Funções - 12\%. Verificaram, ainda, que, $49 \%$ das observações se referiam à inexistência de $\mathrm{DCl}$, o que contraria a expectativa da CVM.

Dentre a literatura internacional que versa sobre Red Flags e/ou DCI foram identificados os estudos sintetizados no Apêndice A.

\section{Procedimentos Metodológicos}

\subsection{Classificação, Amostra e Coleta de dados}

A pesquisa classificou-se como descritiva, documental e com abordagem quantitativa. Os dados amostrais referentes ao período de 2010 a 2018 foram obtidos a partir dos Formulários de Referência, disponíveis no sítio eletrônico da Comissão de Valores Mobiliários (CVM), e na base de dados da ComDinheiro, em relação às 96 empresas que compunham o Índice Brasil 100 (IBRX 100) em 31 de dezembro de 2018. Eles foram analisados por meio do software Stata 16. Destaca-se que Bradesco, Cemig, Eletrobras e Petrobras possuem dois títulos na carteira e, por esse motivo, o total de títulos não coincide com o total de empresas.

A utilização dessa amostra, não probabilística, fundamenta-se na representatividade das empresas em termos de volume de negociações na Bolsa de Valores brasileira B3. Considera-se que a probabilidade dessas empresas serem auditadas por uma Big4 é maior, logo, elas estão sujeitas a uma maior detecção de $\mathrm{DCl}$ por estarem expostas a maiores responsabilidade legal, risco de litígio e reputação (Ge \& McVay, 2005). Por sua vez, o período selecionado decorre da entrada em vigência da ICVM no 480 de 2009 , que passou a exigir o detalhamento das $\mathrm{DCl}$ encontradas pelo auditor independente no Formulário de Referência das entidades.

\subsection{Técnicas de Análise de Dados}

Inicialmente, foram utilizadas técnicas de análise de conteúdo para classificação das Deficiências de Controles Internos (DCl) reportadas no período, conforme as categorias definidas por Ge e McVay (2005): Contas Contábeis Específicas; Treinamento de Profissional Contábil; Políticas de Relatórios/Contabilidade em final de período; Reconhecimento de Receita; Segregação de Funções; Reconciliação de Contas; Subsidiária Específica; Gerenciamento Sênior; Problemas de Tecnologia.

Dado que as informações sobre as DCl são qualitativas e não padronizadas, o processo de leitura e categorização passou por dupla revisão. Essa fase foi documentada por um protocolo de pesquisa e livro de codificação, conforme recomenda Saldaña (2012). Na sequência utilizou-se a estatística descritiva para 
analisar as características e frequências das $\mathrm{DCl}$ e demais variáveis estudadas. A análise descritiva foi realizada conjuntamente com os testes de diferenças entre as médias, medianas e proporções, de modo a se obter indícios de associação entre os grupos e variáveis estudados. Segundo Fávero (2015), o objetivo destes testes é verificar a significância estatística de tais diferenças entre os grupos, tal como: empresas que reportaram e as que não reportaram DCl, níveis de governança, segmento econômico, tipo de auditor, ano, entre outros fatores. Por fim, realizou-se uma análise de regressão por meio de um modelo Logístico e outro de Poisson. O objetivo da regressão logística é estimar a probabilidade de ocorrência de determinado evento, que, no presente estudo, configura-se na divulgação de uma DCl. A avaliação da qualidade do modelo foi realizada por meio da: sensitividade, especificidade e o percentual de classificação correta, recomendadas por Wooldridge (2011).

Adicionalmente, estimou-se um modelo de Poisson, utilizado para dados de contagem (Wooldridge, 2011), tendo em vista que se buscou verificar se as red flags testadas explicavam as quantidades de DCl reportadas pelas empresas participantes da amostra. Em ambos os casos foi utilizada a estimação, por meio de Pooled com controles de ano e setor. Destaca-se que os resultados do modelo Logit estão apresentados pela Razão de Chances (RZ) ou ODD Ratios (OR), e, no contexto deste estudo, pode-se considerar a probabilidade das empresas que apresentaram aumento dos accruals discricionários reportarem uma $\mathrm{DCl}$ dividida pela probabilidade das que não apresentaram aumento nos accruals reportarem uma $\mathrm{DCl}$. Além disso, estimou-se o efeito marginal $\left(\frac{\partial y}{\partial x}\right)$, que consiste na variação em $\mathrm{y}=\mathrm{p}$ (DCl), dada uma variação em $X_{i t}$, como, por exemplo, o tamanho da empresa. No presente estudo, a utilização do efeito marginal possibilita a identificação do potencial efeito econômico que as red flags têm sobre a probabilidade de reporte de uma $\mathrm{DCl}$, indicando o quanto y varia em função de $\mathrm{x}$.

\subsection{Variáveis e Modelos}

A equação (1) foi utilizada para estimação de um modelo de regressão, do tipo Logit e uma variação com modelo de Poisson (Tab.3). No modelo logit (1.3) a variável explicada (DCl) foi operacionalizada como dummy e no modelo de Poisson (1.4), como variável discreta de contagem (QTDEDCI). As variáveis explicativas de interesse foram as red flags propostas por Beneish (1999) e Grove e Cook (2004). O Apêndice $B$ apresenta a operacionalização das variáveis utilizadas nos modelos.

$$
\mathrm{DCI}_{\mathrm{it}}=\beta_{0}+\sum_{\mathrm{i}=1}^{9} \beta_{\mathrm{j}} \text { RedFlags }_{\mathrm{it}}+\sum_{\mathrm{i}=1}^{6} \beta_{\mathrm{k}} \text { Controles }_{\mathrm{it}}+\varepsilon_{\mathrm{it}}
$$

\subsubsection{Variáveis Dependentes}

A variável dependente do modelo é a Deficiência de Controles Internos ( $\mathrm{DCI}_{\mathrm{it}}$ ), operacionalizada como uma variável dummy, que assumiu valor 1 quando a empresa reportou 1 ou mais $\mathrm{DCl}$, e zero, quando não. Além disso, a DCl foi operacionalizada como uma variável discreta, com o logaritmo da quantidade de $\mathrm{DCl}$ reportadas em cada firma/ano. Essa abordagem foi utilizada por Ge e McVay (2005), classificando-as por categorias. A análise de classificação também foi adotada em pesquisas brasileiras, como as de Teixeira e Cunha (2016) e Lopes, Marques e Louzada (2019).

\subsubsection{Variáveis Independentes}

Um dos pioneiros nos estudos sobre red flags quantitativas, Beneish (1999), desenvolveu um modelo estatístico para detectar demonstrações fraudulentas a partir das variáveis de alerta, e, com isso, diversos autores desenvolveram suas pesquisas sobre o tema. É o caso de Wells (2001), que buscou explicar as red flags significativas de Beneish (1999), e de Grove e Cook (2004), que usaram as variáveis significativas para analisar empresas envolvidas em fraudes: Enron, WorldCom, Global Crossing e Qwest. Sendo assim, este estudo utilizou as mesmas red flags quantitativas dos estudos anteriores, a saber: Índice de Dias de Vendas em Recebíveis (IDVR); Índice de Margem Bruta (IMB); Índice de Qualidade dos Ativos (IQA); Índice de Crescimento de Vendas (ICV); Total de Accruals para o Total de Ativos (TATA); Índice de Depreciação (ID); Índice de Despesas de Vendas, Gerais e Administrativas (IDVGA); Índice de Alavancagem (IA); e Índice de Qualidade dos Lucros (IQL).

Este artigo buscou usar as mesmas variáveis, sendo elas detalhadas por Beneish (1999) e Grove e Cook (2004) como red flags e descritas a seguir. A variável IDVR consiste em uma red flag, pois o seu aumento exagerado pode estar vinculado à manipulação de receita, sugerindo uma mudança na política de crédito para estimular as vendas ou a inflação de receita. Logo, espera-se que aumentos no IDVR estejam associados positivamente com a divulgação de uma DCl. Já o IMB sinaliza que uma redução da margem bruta é vista como algo ruim para a empresa, e, dessa forma, haveria incentivos para a manipulação de lucros como forma de compensação da queda operacional, tornando positivo o sinal esperado para essa variável. A variável IQA captura a possibilidade de capitalização e manipulação de custos como forma de 
amenizar a diminuição do desempenho econômico, e, por isso, espera-se um sinal positivo. A variável ICV mede o aumento das vendas de um ano para outro, sinalizando a manipulação nos números quando esse aumento é abrupto. Por esse motivo, espera-se uma associação positiva com a divulgação de uma DCl. A variável TATA, por sua vez, avalia o nível de accruals totais que podem sofrer variações bruscas em decorrência de manipulações intencionais. Quanto maior o nível de accruals, maior a probabilidade de manipulação e, portanto, maior a probabilidade de reporte de uma DCl. A variável ID mensura as variações da taxa de depreciação. Quando a taxa diminui, indica que a empresa pode ter aumentado a vida útil de seus ativos ou o método utilizado de forma a aumentar o lucro, e, portanto, espera-se uma associação negativa com a divulgação de um DCl.

A variável IDVGA, por seu turno, captura o risco de manipulação dos resultados por antecipação ou postergação de despesas, bem como a manipulação intencional das vendas. Mudanças significativas na relação entre DVGA sinalizam manipulação de resultados por operações reais e/ou fraudes, e, por esse motivo, espera-se maior uma associação positiva com a divulgação de um DCl. Já o IA captura os incentivos relacionados à cobertura de dívida. Quanto maior este índice, maior a chance de manipulação de resultados, logo, maior risco de reporte de uma DCI. Por fim, o IQL mede a qualidade dos lucros; logo, quanto maior for esse índice, menor a probabilidade de uma manipulação intencional dos lucros, pois evidencia um maior volume de accruals. Em termos de risco de associação com a divulgação de um DCI, espera-se que aumentos do IQL estejam associados negativamente com a divulgação de uma DCl.

\subsubsection{Variáveis de Controle}

As variáveis de controle foram as propostas por Beneish (1999), Doyle at al. (2007) e Marques et al. (2017), a saber: Idade da Firma (Idade), Nível de Governança (NM), Republicação Obrigatória (RepObr), Tamanho da Firma (TAM). A variável Idade representa o número de anos de listagem no mercado (Doyle at al., 2007). A variável NM refere-se a uma dummy que assume valor 1 para Nível de Governança (N1, N2 ou NM) e zero para tradicional, enquanto a variável RepObr é caracterizada como uma dummy que assume valor 1 quando houver republicação obrigatória da demonstração e zero quando espontânea (Doyle at al., 2007; Marques at al., 2017). A variável TAM foi obtida a partir do logaritmo do total do Ativo da empresa i no ano t (Beneish, 1999; Doyle at al., 2007; Marques et al., 2017). Em relação aos sinais, espera-se que as variáveis RepObr e TAM apresentem sinal positivo, com uma relação diretamente proporcional à divulgação de DCl. A variável NM, por sua vez, apresenta sinal negativo, inversamente proporcional à probabilidade de DCl (Doyle at al., 2007; Marques et al., 2017).

\section{Análise de Dados e Discussão dos Resultados}

\subsection{Estatística Descritiva e Diferenças entre os Grupos}

Inicialmente, analisou-se a distribuição de frequência das informações reportadas sobre as Deficiências de Controles Internos (DCI) no período de 2010 a 2018 pelas empresas do IBRX 100, dividindo-se a Tabela 1 em três painéis: Painel A - Nível de Governança; Painel B - Empresa de Auditoria e Painel C - Segmento Econômico. Em uma análise geral, verificou-se que, das 864 observações, 185 apresentaram Deficiências de Controles Internos (DCI), 502 não apresentaram deficiências (SDCI) e 104 apresentaram Deficiências Não Significativas (DNS).O Painel A evidencia que 62,5\% das observações se referem a empresas listadas no Segmento Novo Mercado. A rigor, são aquelas que adotam as melhores práticas de governança corporativa.

Em média, as empresas listadas nos segmentos Tradicional (TRAD), Nível 1 (N1), Nível 2 (N2) e Novo Mercado (NM) reportaram, respectivamente, 1,88; 1,65; 2,36 e 1,93 DCl no período de 2010 a 2018. Verificou-se que as empresas listadas no Nível 2 tenderam a reportar mais $\mathrm{DCl}$, seguidas pelas do NM. $\mathrm{O}$ teste de diferença entre proporções evidenciou que a proporção de DCI reportadas pelas empresas listadas no segmento N1 é menor (Dif: $-0.0576036|z=-1.5095| \operatorname{Pr}(Z>z)=0,0656$ ) e estatisticamente significativa ao nível de 10\%. Já as empresas do N2 apresentaram proporção média superior e estatisticamente significativa (Dif: $0.0786969|z=1.6327| \operatorname{Pr}(Z>z)=0,0513)$ em relação às demais, também ao nível de $10 \%$. Observou-se ainda que as empresas listadas nos segmentos N2 e NM tendem a apresentar maiores proporções de $\mathrm{DCl}$, o que converge com a expectativa de maior transparência das empresas com maiores níveis de governança, corroborando, pois, os achados de Doyle et al. (2007) e Lopes et al. (2019). Por outro lado, há de se entender que, se tais $\mathrm{DCl}$ são persistentes ou eventuais, caso sejam persistentes, podem evidenciar a dificuldade da empresa em mitigá-las, mesmo estando em níveis de governança diferenciados.

Brickley e Zimmerman (2013) destacaram que a literatura sobre governança corporativa tem reforçado alguns mitos, entre eles o de que uma "boa governança" pode ser capturada por dados. Os autores supramencionados observaram que há que se compreender em profundidade sobre a sua efetividade, o que converge para a aparente incoerência observada na comparação da proporção de $\mathrm{DCl}$ reportadas nos níveis TRAD e N1, que apresentaram menos DCl do que os segmentos considerados como de boas práticas de governança, N2 e NM. 
Tabela 1:

Distribuição de Frequência por Tipo de Informação sobre Deficiências de Controles Internos Reportadas no Período de 20102018 pelas Empresas do IBRX100

Painel A - Por Nível Governança

\begin{tabular}{|c|c|c|c|c|c|c|c|c|}
\hline & $\mathrm{n}$ & $\mathrm{DCl}$ & SDCl & DNS & ND/SD & Total & fri. & fra. \\
\hline Nível 1 (N1) & 17 & 28 & 107 & 16 & 2 & 153 & $17.71 \%$ & $17.71 \%$ \\
\hline Nível 2 (N2) & 11 & 26 & 54 & 6 & 13 & 99 & $11.46 \%$ & $29.17 \%$ \\
\hline Novo Mercado (NM) & 60 & 116 & 292 & 76 & 56 & 540 & $62.50 \%$ & $91.67 \%$ \\
\hline Tradicional (TRAD) & 8 & 15 & 49 & 6 & 2 & 72 & $8.33 \%$ & $100.00 \%$ \\
\hline Total & 96 & 185 & 502 & 104 & 73 & 864 & $100.00 \%$ & \\
\hline \multicolumn{9}{|l|}{ Painel B - Por Empresa de Auditoria } \\
\hline Deloitte Touche Tohmatsu (DTT) & 45 & 40 & 103 & 6 & 1 & 150 & $17.36 \%$ & $17.36 \%$ \\
\hline Ernst \& Young (EY) & 51 & 37 & 120 & 2 & 9 & 168 & $19.44 \%$ & $36.81 \%$ \\
\hline KPMG & 65 & 53 & 146 & 27 & 10 & 236 & $27.31 \%$ & $64.12 \%$ \\
\hline PriceWaterhouseCoopers (PWC) & 44 & 47 & 106 & 19 & 12 & 184 & $21.30 \%$ & $85.42 \%$ \\
\hline Outras (NBig4) & 12 & 8 & 27 & 50 & 41 & 126 & $14.58 \%$ & $100.00 \%$ \\
\hline Total & & 185 & 502 & 104 & 73 & 864 & $100.00 \%$ & \\
\hline \multicolumn{9}{|l|}{ Painel C - Por Segmento Econômico } \\
\hline Bens Industriais $(\mathrm{BI})$ & 8 & 16 & 43 & 4 & 9 & 72 & $8.33 \%$ & $8.33 \%$ \\
\hline Comunicações (COM) & 2 & 4 & 14 & 0 & 0 & 18 & $2.08 \%$ & $10.42 \%$ \\
\hline Consumo Cíclico (CC) & 20 & 52 & 87 & 29 & 12 & 180 & $20.83 \%$ & $31.25 \%$ \\
\hline Consumo Não Cíclico (CNC) & 9 & 18 & 38 & 15 & 10 & 81 & $9.38 \%$ & $40.63 \%$ \\
\hline Financeiro (FIN) & 17 & 7 & 118 & 9 & 19 & 153 & $17.71 \%$ & $58.33 \%$ \\
\hline Materiais Básicos (MB) & 10 & 13 & 69 & 8 & 0 & 90 & $10.42 \%$ & $68.75 \%$ \\
\hline Petróleo, Gás e Bioc. (PGB) & 5 & 7 & 30 & 2 & 6 & 45 & $5.21 \%$ & $73.96 \%$ \\
\hline Saúde (SAU) & 6 & 22 & 12 & 6 & 14 & 54 & $6.25 \%$ & $80.21 \%$ \\
\hline Tecnologia da Informação (TI) & 3 & 7 & 12 & 5 & 3 & 27 & $3.13 \%$ & $83.33 \%$ \\
\hline Utilidade Pública (UP) & 16 & 39 & 79 & 26 & 0 & 144 & $16.67 \%$ & $100.00 \%$ \\
\hline Total & 96 & 185 & 502 & 104 & 73 & 864 & $100.00 \%$ & \\
\hline fri. & & $21.41 \%$ & $58.10 \%$ & $12.04 \%$ & $8.45 \%$ & $100.00 \%$ & & \\
\hline
\end{tabular}

Nota: DCl - Com Deficiências de Controles Internos; SDCl - Sem Deficiências de Controles Internos; DNS - Deficiências de

Controles Internos não Significativas; SD - Sem Detalhamento de Deficiências de Controles Internos; ND - Não Disponível.

Verificou-se, ainda, que $33,45 \%$ do total de 864 observações apresentaram algum tipo de $\mathrm{DCl}$, significativa ou não. Esse percentual se refere a um total de 75 das 96 empresas, o que representa $78,13 \%$ do total de empresas participantes da amostra. Além disso, 21 empresas não reportaram $\mathrm{DCl}$ em nenhum dos anos analisados. Segundo a CVM (2009), a inexistência de DCI deveria ser uma situação excepcional, logo, a proporção de: Sem Deficiências de Controles Internos (SDCl) deveria ser zero ou próximo disso. Por outro lado, como a divulgação de $\mathrm{DCl}$ pode gerar efeitos adversos aos gestores, é possível que eles selecionem e/ou evitem divulgar as DCl existentes (Lenard et al., 2016). Destaca-se que as empresas COGNA Educação e Hypera Pharma foram as que mais reportaram variadas classificações de $\mathrm{DCl}$ no período (20), sendo por isso consideradas como significativas no total.

A análise da distribuição de frequência por empresa de auditoria (Painel B) demonstra que as empresas Big4 responderam por $85,42 \%$ das observações. Em média, aquelas que foram acompanhadas pelas empresas de auditoria DTT, EY, KPMG e PWC reportaram, respectivamente, 0,89, 0,74, 0,82 e 1,07 $\mathrm{DCl}$ ao longo do período. Já as empresas auditadas pelas não Big4 reportaram, em média, 0,67. Esses resultados sugerem que as que foram auditadas pelas não Big4 apresentam menores quantidades de DCl, o que converge com a perspectiva de Rice e Weber (2012) e de Ge e McVay (2005), que afirmaram que os clientes das Big4, por serem maiores, tendem a ter igual ou maior probabilidade de detecção de $\mathrm{DCl}$ devido ao maior risco de litígio e de reputação. Assim, as evidências anteriores são reiteradas no sentido de que há uma melhor estrutura de controle nas empresas auditadas pelas Big4 (Ge \& McVay, 2005; Doyle et al., 2007; Rice \& Weber, 2012). Contudo, Lenard et al. (2016) encontraram evidências de que ser auditado por uma não Big4 aumenta a probabilidade de reporte de DCl.

Por fim, o Painel $C$ evidencia que os setores de CC (Dif: $0.0980771|z=2.6749| \operatorname{Pr}(Z>z)=$ 0,0037 ) e SAU (Dif: $0.3346764|z=4.8862| \operatorname{Pr}(Z>z)=0.000$ ) foram os que apresentaram maior proporção de $\mathrm{DCl}$ reportadas - em média, 2,60 e 3,67, respectivamente, por empresa. Já os setores FIN (Dif: $0.2162378|z=-5.4076| \operatorname{Pr}(Z>z)=0,0000)$ e MB (Dif: $-0.144444|z=-2.0918| \operatorname{Pr}(Z>z)=0.0182)$ foram os que apresentaram menores proporções - em média, 0,41 e 1,30 por empresa, ao longo do período. $O$ teste de diferença de proporções demonstrou diferenças estatisticamente significativas aos níveis de 1\%, $5 \%$ e $10 \%$. Esses resultados são consistentes com as diferenças setoriais encontradas em Gullkvist e Jokipii (2013) e em Bolton et al. (2016). Destaca-se que os setores FIN e SAU são considerados complexos pela natureza de suas operações. A complexidade do setor é um fator determinante da divulgação de DCI (Ge \& Mcvay, 2005; Doyle et al., 2007; Bolton et al., 2016). Entretanto, enquanto no setor financeiro a proporção de $\mathrm{DCl}$ foi inferior aos demais, no setor de saúde a proporção foi comparativamente superior ao dos demais setores.

A Figura 1 apresenta a distribuição de frequência por tipo de DCI reportadas no período de 2010 a 2018 pelas empresas do IBRX 100. 


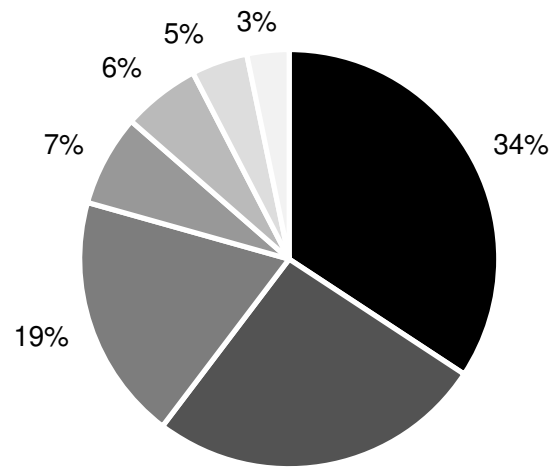

$26 \%$

\author{
- Política Contábil \\ - Falhas Tecnológicas \\ - Contas Específicas \\ - Falhas em Subsidiárias \\ - Reconciliação de Contas \\ Reconhecimento de Receita \\ Outras DCls
}

Figura 1 - Distribuição de Frequência por Tipo de Deficiência Significativas de Controles Internos, Reportadas no Período de 2010-2018 pelas Empresas do IBRX 100

Nota: A categoria - Outras DCls agrupam as deficiências com: Treinamento, Gerência Sênior, Segregação de Função.

Verifica-se que as DCI relacionadas à Política Contábil (PC) - 34\%, Falhas Tecnológicas (FT) - 26\% e Contas Específicas (CE) - 19\% foram as predominantes. Juntas, representam cerca de $80 \%$ das DCl significativas reportadas no período. O teste de diferença de proporção reforçou a predominância dessas três $\mathrm{DCl}$, quando comparadas com as demais. Nos três casos, o teste de diferença entre proporções demonstrou que PC (Dif: $0.9120755|z=22.2507| \operatorname{Pr}(Z>z)=0.0000$ ), FT (Dif: $0.8730385|z=19.0018|$ $\operatorname{Pr}(Z>z)=0.0000)$ e CE (Dif: $0.8418157|z=15.9331| \operatorname{Pr}(Z>z)=0.0000$ ) têm, em média, maior proporção - em todas elas, estatisticamente significativas ao nível de $1 \%$.

Os resultados observados no presente estudo convergem parcialmente com os achados de $\mathrm{Ge} e$ McVay (2005), Lopes et al. (2016) e Teixeira e Cunha (2016). Nos estudos de Ge e McVay (2005), as DCl predominantes foram referentes a Contas Específicas (CE) e Treinamento (agrupada na categoria Outras DCls). Para Lopes et al. (2016), as mais recorrentes foram Treinamento, Falhas Tecnológicas (FT) e Falhas em Subsidiárias (FS). Já nos achados de Teixeira e Cunha (2016), as mais representativas foram Falhas Tecnológicas (FT), Política Contábil (PC) e Outras DCls.

De acordo Ge e McVay (2005), as DCI relacionadas às Políticas Contábeis decorrem de aplicação inadequada das políticas de reconhecimento, mensuração e divulgação. As $\mathrm{DCl}$ relacionadas às Falhas Tecnológicas incluem as deficiências relacionadas ao acesso, manutenção e segurança dos dados e sistemas. Por fim, as $\mathrm{DCl}$ referentes às Contas Específicas se referem a outras deficiências não categorizadas dentre as demais, cujas frequências não são persistentes.

Na sequência, a Tabela 2 - Estatística Descritiva das Red Flags por grupos, compara as médias dos grupos de empresas que reportaram $\mathrm{DCl}$ significativas e as que não reportaram $\mathrm{DCl}$ (SDCl). As red flags utilizadas foram propostas por Beneish (1999) e Grove e Cook (2004): a rigor, quanto maiores, maior será o potencial de ocorrência de fraude/erro (Beneish, 1999). Desse modo, comparando-se as médias, espera-se que as empresas que reportaram DCl tenham as médias das red flags superiores.

Tabela 2:

Estatística Descritiva das Red Flags por Grupos

\begin{tabular}{|c|c|c|c|c|c|c|c|c|c|c|}
\hline \multirow[b]{3}{*}{ Variáveis } & \multicolumn{5}{|c|}{ Sem Deficiências de Controles Internos } & \multicolumn{5}{|c|}{ Com Deficiências de Controles Internos } \\
\hline & \multicolumn{5}{|c|}{$\begin{array}{c}\text { Sem DCI (0) } \\
\mathrm{N}=612\end{array}$} & \multicolumn{5}{|c|}{$\begin{array}{c}\text { Com DCI (1) } \\
\mathrm{N}=185\end{array}$} \\
\hline & $\mathrm{n}$ & $\mu$ & $\sigma$ & Min & Max & $\mathrm{n}$ & $\mu$ & $\sigma$ & Min & $\operatorname{Max}$ \\
\hline IDVR & 478 & 1,0425 & 0,7662 & 0,0000 & 11,7966 & 143 & 1,0193 & 0,4199 & 0,0000 & 3,4243 \\
\hline IQA & 538 & $1,1721 \mathrm{ab}$ & 0,6832 & 0,1156 & 7,2065 & 179 & $1,0273^{a b}$ & 0,2350 & 0,3847 & 2,7234 \\
\hline IMB & 512 & $1,0384^{a}$ & 0,3009 & 0,1357 & 5,2122 & 173 & $0,9638^{a}$ & 0,7032 & $-4,7598$ & 4,7544 \\
\hline ICV & 580 & $1,2162^{a b}$ & 1,6038 & 0,0316 & 38,9429 & 176 & $1,1031 \mathrm{ab}$ & 0,2475 & 0,3467 & 2,5240 \\
\hline ID & 529 & $1,0187 a b$ & 0,3902 & 0,0261 & 5,5146 & 173 & $0,9629 a b$ & 0,1956 & 0,1520 & 1,8447 \\
\hline IDVGA & 512 & 1,0119 & 1,5449 & $-2,1441$ & 18,3363 & 173 & 1,2524 & 2,5014 & $-1,9631$ & 33,1796 \\
\hline $\mathrm{IA}$ & 511 & $1,0142^{a}$ & 0,1808 & 0,3633 & 2,3247 & 169 & $1,0576 a$ & 0,3318 & 0,4451 & 4,1656 \\
\hline TATA & 589 & 1,1996 & 2,1959 & $-1,8888$ & 395,0724 & 178 & 1,8717 & 8,7640 & $-11,1375$ & 89,4263 \\
\hline TAM & 610 & 23,4806 & 1,6287 & 16,9027 & 28,0711 & 185 & 23,3358 & 1,3085 & 20,6097 & 27,5258 \\
\hline IQL & 601 & 1,7086 & 1,3136 & $-1,2496$ & 229,3554 & 183 & 0,9901 & 24,6514 & $-209,8895$ & 184,6429 \\
\hline IDADE & 579 & $10,1605^{a b}$ & 8,9981 & 2,5649 & 23,0239 & 174 & $8,7244 \mathrm{ab}$ & 8,4941 & 3,0257 & 23,0222 \\
\hline
\end{tabular}

Fonte: Dados da pesquisa. ${ }^{a}$ estatisticamente significativos a $1 \%, 5 \%$ ou $10 \%$ por meio do teste t. ${ }^{b}$ estatisticamente significativos a $1 \%$, $5 \%$ ou $10 \%$ mediante o teste Kruskall-Wallis. IDVR - Índice de Dias de Vendas em Recebíveis; IQA - Índice de Qualidade dos Ativos; IMB - Índice de Margem Bruta; ICV - Índice de Crescimento de Vendas; ID - Índice de Depreciação; IDVGA - Índice de Despesas de Vendas, Gerais e Administrativas; IA - Índice de Alavancagem; TATA - İndice de Total de Accruals (provisões) para o Total de Ativos; IQL - Índice de Qualidade dos Lucros; TAM - Variável contínua obtida a partir do logaritmo natural dos ativos totais da empresa; IDADE - Variável contínua obtida a partir do logaritmo natural dos anos de registro da empresa na CVM. 
Verificou-se que, das 11 variáveis apresentadas, em 8 delas as médias do grupo de empresas que não reportaram $\mathrm{DCl}$ foram superiores às daquelas que o fizeram. Entretanto, as diferenças entre as médias só foram estatisticamente significativas para IQA, IMB, ICV, ID, IA e Idade. A identificação de diferenças significativas é uma evidência inicial de que as empresas que reportam $\mathrm{DCl}$ tendem a apresentar maiores médias para as red flags quando comparadas com as que não reportaram $\mathrm{DCl}$, constituindo-se uma evidência inicial de que empresas que apresentam maiores red flags estão associadas à maior divulgação de uma DCl.

Esses resultados primários convergem com as evidências apresentadas por Beneish (1999) e Su, Zhao e Zhou (2014), que verificaram que empresas que manipularam as demonstrações financeiras, e aquelas que reportaram $\mathrm{DCl}$, apresentavam red flags superiores e estatisticamente significativas. Nesse estudo, dentre as variáveis que apresentaram significância estatística, excetuando-se a variável IA, todas as demais apresentaram médias superiores para o grupo das empresas que não reportaram DCI. Esse resultado pode sinalizar uma resistência das empresas em reportarem $\mathrm{DCl}$, mesmo apresentando sinais de erros ou manipulações, o que é coerente com as perspectiva de Lenard et al. (2016), quando afirmaram que os gestores podem evitar reportar uma $\mathrm{DCl}$ a fim de reduzirem os seus efeitos adversos, tais como: custo político (Li et al., 2018) e a redução dos preços das ações (Hammersley et al., 2008).

\subsection{Associação entre as Red Flags e a Divulgação de Deficiências de Controles Internos}

Por fim, a Tabela 3 apresenta o resultado do modelo de regressão logístico (1.1 a 1.3) e o modelo de Poisson (1.4). Inicialmente, estimou-se o efeito das red flags (1.1 e 1.2) diferenciando-se apenas pelo controle de ano e setor, realizado no modelo 1.2. Verifica-se que houve uma melhoria geral na capacidade de acertos quando controlados os efeitos ano e setor. Essa melhoria é coerente com a observância de diferenças estatisticamente significativas entre os setores discutidos anteriormente. No modelo 1.3, estimouse uma regressão logística, igualmente, com controle de ano e setor e com a inclusão de outras variáveis de controle observadas em Beneish (1999) e Doyle et al. (2007). Tais inclusões melhoraram os resultados gerais do modelo nos três principais indicadores de qualidade, a saber: sensitividade; especificidade; e percentual de acertos (Wooldridge, 2011). Logo, o modelo 1.3 foi a base de interpretação do fenômeno de interesse. Por fim, por meio do modelo 1.4, estimou-se uma regressão para dados de contagem (Poisson).

Considerando o modelo logístico 1.3 como a base para a análise do fenômeno de interesse, dados os indicadores de qualidade propostos pela literatura e observando as indicações de Wooldridge (2011), analisou-se o efeito das red flags sobre o reporte de $\mathrm{DCl}$ por meio Idade $_{\mathrm{t}}$ da razão de chances e do efeito marginal. Nesse ínterim, verificou-se que as variáveis IDVR $\left(-0,818^{*} \mid-0,0938^{* *}\right)$, ICV $\left(-2,639{ }^{* \star *} \mid-\right.$ $\left.0,3027^{* *}\right)$ e ID $\left(-2,233^{* * *} \mid-0,2561^{* * *}\right)$ apresentaram efeito negativo e estatisticamente significativo. Já a variável IA $\left(2,709^{\star * *} \mid 0,3108^{* * *}\right)$ apresentou efeito positivo e estatisticamente significativo.

Além disso, observou-se que as variáveis de controle $\operatorname{Idade}_{t}\left(0,0619^{\star} \mid 0,0071^{* *}\right)$ e $\operatorname{RepObr}_{t-1}$ $\left(0,419^{* *} \mid 0,0480^{* \star}\right)$ apresentaram efeito positivo sobre o reporte de uma DCl. Do ponto de vista econômico, observa-se que aumentos de $1 \%$ nas red flags IDVR, ICV e ID reduzem em aproximadamente 9,38\%, $30,27 \%$ e $25,61 \%$, respectivamente, a probabilidade de ocorrência de uma DCI. Por sua vez, o aumento de $1 \%$ na red flag IA aumenta em torno de $31,08 \%$ a probabilidade de reporte de uma DCI. Além disso, aumentos de $1 \%$ na idade da firma e no fato de a empresa ter republicado as demonstrações no ano anterior aumentam em torno de $0,71 \%$ e 4,8\% a probabilidade de reporte de uma $\mathrm{DCl}$, respectivamente.

No modelo 1.4 (Poisson) verificou-se convergência dos resultados observados no modelo 1.3. As red flags DSRI $\left(-0,768^{*}\right)$, SGI $\left(-1,147^{* * *}\right)$ e DEPI $\left(-0,677^{*}\right)$ apresentaram efeito negativo e estatisticamente significativos sobre a probabilidade de divulgação de uma DCI. Já as red flags GMI $\left(0,729^{\star *}\right)$ e LVGI $\left(1,505^{\star \star}\right)$ apresentaram efeito positivo sobre o reporte de uma DCl. Observou-se ainda que as variáveis de controle $\mathrm{QL}_{\mathrm{t}}\left(-0,009^{\star * *}\right)$ e $\mathrm{NM}\left(-1,106^{\star * *}\right)$ apresentaram efeito negativo e a $\operatorname{Idade}_{\mathrm{t}}\left(0,0282^{\star *}\right)$ apresentou efeito positivo. Em termos gerais, os resultados do modelo 1.4 (Poisson) reforçam as evidências observadas no modelo 1.3 (Logit), adicionando a evidência de que a qualidade dos lucros está associada ao menor reporte de $\mathrm{DCl}$ e de que empresas listadas nos níveis de governança tendem a reportar menor quantidade de DCl.

Os resultados obtidos nesta investigação divergem, em parte, da literatura sobre manipulação de resultados (Beneish, 1999) na medida em que evidenciam que, no contexto brasileiro, as red flags estão associadas ao menor reporte de DCl. Por um lado, essa menor divulgação de DCl pode decorrer da maior atenção dada pelo auditor em decorrência da sinalização do risco de erro ou manipulação das informações a partir das red flags. Isso faria com que os auditores exigissem ações corretivas em tempo hábil para mitigar as deficiências e suas implicações nas demonstrações contábeis. Ge e McVay (2005) reforçam que as grandes empresas, apesar de estarem expostas a um maior risco de existência de uma DCl, possuem recursos necessários para mitigá-lo. 
Tabela 3:

Estatística dos Modelos de Regressão para Estimação do Efeito dos Red Flags sobre as DCls

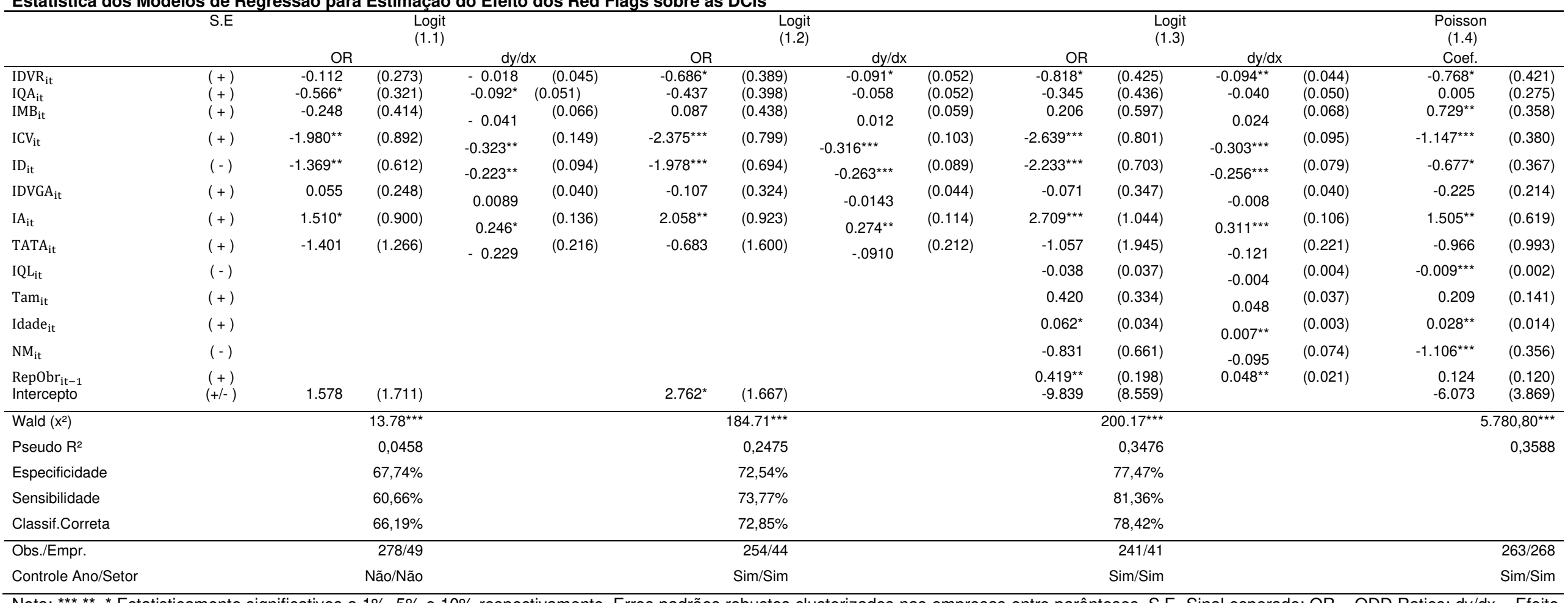

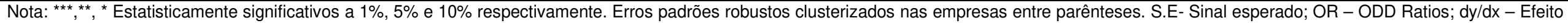
marginal da iésima variável. 
Por outro lado, pode decorrer das características da amostra, composta pelas principais empresas do mercado de capitais brasileiro. Logo, a frequência de fragilidades significativas é menor em decorrência do tamanho e da estrutura de governança das mesmas. Além disso, o sistema de incentivos das grandes empresas busca estimular a evolução permanente dos seus sistemas de controles internos (Liu \& Liu, 2017). Ademais, esse efeito marginal negativo das red flags pode decorrer da omissão ou da falta de transparência na divulgação das deficiências de controles internos. Dada a existência de um potencial efeito adverso por parte do mercado, os gestores, auditores e demais agentes possuem incentivos para a não divulgação das DCl (Hammersley et al., 2008; Li et al., 2018).

\section{Considerações Finais}

O objetivo do presente estudo foi analisar o efeito das Red Flags de Auditoria (RFA) sobre a divulgação de Deficiências de Controles Internos (DCl) das empresas de capital aberto que compõem 0 Índice Brasil 100 (IBRX 100), listadas na B3. Os resultados evidenciaram que em torno de 78,13\% das empresas listadas no IBRX 100 reportaram $\mathrm{DCl}$, sugerindo relativa qualidade na transparência dos controles internos das empresas, uma vez que as deficiências estão sendo detectadas e evidenciadas pela maioria das empresas do índice. As DCI relacionadas às Políticas Contábeis, Falhas Tecnológicas e Contas Específicas representam em torno de $80 \%$ do total, corroborando parcialmente os resultados de Ge e McVay (2005). Nesse âmbito, os setores de Materiais Básicos e Financeiro são os que menos reportaram, enquanto os de Saúde e Consumo Cíclico foram os que mais reportaram DCl.

Observou-se que as red flags propostas por Beneish (1999) apresentaram, em sua maioria, efeito de associação negativa com a divulgação de $\mathrm{DCl}$, conforme visualizado na Tabela 3 . Esse resultado contraria, em parte, a literatura sobre manipulação e qualidade dos lucros, entretanto, características da amostra ou do ambiente institucional não exploradas por esse estudo podem ter influenciado tal resultado.

Por um lado, os gestores brasileiros podem resistir em divulgar uma $\mathrm{DCl}$ em decorrência dos efeitos adversos na avaliação de risco e precificação das ações. Por outro, as empresas que compõem o IBRX 100 , além de serem aquelas com maior volume de negociações entre as listadas, em sua maioria estão posicionadas nos níveis diferenciados de governança (NM, N2 e N1), logo, suas estruturas de controles internos não apresentam, de fato, deficiências significativas. Porém, segundo a CVM, tal situação deveria ser um caso excepcional.

Zakaria, Nawawi e Salin (2016) observaram que as DCI podem indicar possíveis ocorrências de fraudes ou erros. Sendo assim, os resultados desta pesquisa também contribuem para o debate acerca do papel das red flags como sinalizadores de risco, em especial, um risco de omissão de informações relevantes sobre deficiências de controles internos ou, ainda, uma melhor qualidade da auditoria na medida em que os auditores, a partir das red flags, podem exigir a eliminação ou a mitigação das fragilidades sob pena de emitir uma opinião modificada. Assim como os estudos de Hegazy e Kassem (2010), que concluíram que red flags podem ser úteis aos auditores externos, esta pesquisa também contribui com os gestores, auditores e reguladores ao apresentar evidências que diferem, em alguma medida, da literatura estrangeira, mas reforçam o papel das red flags na avaliação de risco quanto à qualidade das informações contábeis.

Apesar disso, o estudo apresenta limitações relacionadas à amostra em decorrência da exclusão das demais empresas listadas quanto à não utilização do painel logístico, que foi prejudicado em decorrência do tamanho da amostra. Além disso, poderia conciliar técnicas de redução de variáveis para a análise do efeito marginal das RFA sobre as DCl. Como sugestões para pesquisas futuras, indica-se: (i) analisar o efeito das RFA sobre tipos específicos de $\mathrm{DCl}$; (ii) analisar o efeito dos incentivos sobre a publicação das DCl; e ainda (iii) verificar o tipo de associação existente entre as $\mathrm{DCl}$ e as proxies de gerenciamento de resultados por accruals ou operacionais.

\section{Referências}

Baader, G., \& Krcmar, H. (2018). Reducing false positives in fraud detection: combining the red flag approach with process mining. International Journal of Accounting Information Systems, 31, 1-16, dez. https://doi.org/10.1016/j.accinf.2018.03.004

Bauer, T. D., Bucaro, A. C., \& Estep, C. (2020). The unintended consequences of material weakness reporting on auditors' acceptance of aggressive client reporting. The Accounting Review, 95(4), 51-72, 1 jul. https://doi.org/10.2308/accr-52610

Beneish, M. D. (1999). The detection of earnings manipulation. Financial Analysts Journal, 55(5), 24-36, set. https://doi.org/10.2469/faj.v55.n5.2296

Beneish, M. D., Lee, C. M. C., \& Nichols, D. C. (2013). Earnings Manipulation and Expected Returns.

Financial Analysts Journal, 69(2), 57-82. https://doi.org/10.2469/faj.v69.n2.1 
Bolton, B., Lian, Q., Rupley, K., Zhao, J. (2016). Industry contagion effects of internal control material weakness disclosures. Advances in Accounting, 34, 27-40, set. 2016.

https://doi.org/10.1016/j.adiac.2016.07.004

Brasil. Instrução Normativa 308 da Comissão de Valores Mobiliários, de 14 de maio de 1999. Dispõe sobre o registro e o exercício da atividade de auditoria independente no âmbito do mercado de valores mobiliários, define os deveres e as responsabilidades dos administradores das entidades auditadas no relacionamento com os auditores independentes, e revoga as Instruções CVM № 216, de 29 de junho de 1994, e 275, de 12 de março de 1998. http://www.cvm.gov.br

Brasil. Instrução Normativa 480 da Comissão de Valores Mobiliários, de 7 de dezembro de 2009. Dispõe sobre o registro de emissores de valores mobiliários admitidos à negociação em mercados regulamentados de valores mobiliários. http://www.cvm.gov.br

Brasil. Instrução Normativa 552 da Comissão de Valores Mobiliários, de 9 de outubro de 2014. Altera e acrescenta dispositivos à Instrução CVM no 480, de 7 de dezembro de 2009 e altera dispositivos da Instrução CVM no 358, de 3 de janeiro de 2002 e da Instrução CVM no 481, de 17 de dezembro de 2009. http://www.cvm.gov.br

Brickley, J. A., \& Zimmerman, J. L. (2010). Corporate governance myths: comments on armstrong, guay, and weber. Journal of Accounting and Economics, 50(2-3), 235-245, dez. 2010.

https://doi.org/10.1016/j.jacceco.2010.10.002

Cao, J., Luo, X., \& Zhang, W. (2020). Corporate employment, red flags, and audit effort. Journal of Accounting and Public Policy, 39(1), 106710, jan. https://doi.org/10.1016/j.jaccpubpol.2019.106710

Conselho Federal de Contabilidade. (2009). Resolução CFC No. 1.210/09 Aprova a NBC TA 265 Comunicação de Deficiências de Controle Interno. http://www1.cfc.org.br/sisweb/SRE/docs/RES 1210.pdf

Choi, J., Choi, S., Hogan C. E., \& Lee, J. (2013). The effect of human resource investment in internal control on the disclosure of internal control weaknesses. Auditing: A Journal of Practice \& Theory, 32(4), 169-199, nov. 2013. https://doi.org/10.2308/ajpt-50514

Clinton, S. B., Pinello, A. S., \& Skaife, H. A. (2014). The implications of ineffective internal control and SOX 404 reporting for financial analysts. Journal of Accounting and Public Policy, 33(4), 303-327, jul. 2014. https://doi.org/10.1016/i.jaccpubpol.2014.04.005

Donelson, D. C., Ege, M. S., \& Mcinnis, J. M. (2017). Internal control weaknesses and financial reporting fraud. Auditing: A Journal of Practice \& Theory, 36(3), 45-69, ago. https://doi.org/10.2308/ajpt-51608

Doyle, J. T., Ge, W., \& Mcvay, S. (2007). Accruals quality and internal control over financial reporting. The Accounting Review, 82(5), 1141-1170, 1 out. 2007. https://doi.org/10.2308/accr.2007.82.5.1141

Fávero, L. P. (2015). Análise de dados: modelos de regressão com Excel, Stata e SPSS. Rio de Janeiro: Elsevier.

Feroz, E. H., Kwon, T. M., Pastena, V. S., \& Park, K. (2000). The efficacy of red flags in predicting the SEC's targets: an artificial neural networks approach. International Journal of Intelligent Systems in Accounting, Finance \& Management, 9(3), 145-157. https://doi.org/10.1002/1099-1174(200009)9:3<145::aid-isaf185>3.0.co;2-g

Fiirst, C., Pamplona, E., Haag, S., \& Silva, M. Z. (2017). Evidenciação de fatores de riscos de deficiência do controle interno de empresas brasileiras com ADRs. Revista Ciências Sociais em Perspectiva, 16(31), 2017. https://doi.org/10.5935/rcsp.v16i31.15060

Ge, W., Koester, A., \& Mcvay, S. (2017). Benefits and costs of Sarbanes-Oxley Section 404(b) exemption: Evidence from small firms' internal control disclosures. Journal of Accounting and Economics, 63(2-3), 358384, abr. https://doi.org/10.1016/j.jacceco.2017.01.001

Ge, W, \& Mcvay, S. (2005). The disclosure of material weaknesses in internal control after the sarbanesoxley act. Accounting Horizons, 19(3), 137-158, 1 set. https://doi.org/10.2308/acch.2005.19.3.137

Grove, H., \& Basilico, E. (2008). Fraudulent financial reporting detection: key ratios plus corporate 
governance factors. International Studies of Management \& Organization, 38(3), 10-42, set. 2008. https://doi.org/10.2753/IMO0020-8825380301

Grove, H., \& Cook, T. (2004). Lessons for auditors: quantitative and qualitative red flags. Journal of Forensic Accounting, 5, 131-146, 2004.

Grove, H., \& Cook, T. (2007). Fruadulent detection financial reporting detection: corporate governance red flags. Corporate Ownership and Control, 4(4). https://doi.org/10.22495/cocv4i4c2p1

Gullkvist, B., \& Jokipii, A. (2013). Perceived importance of red flags across fraud types. Critical Perspectives on Accounting, 24(1), 44-61, fev. https://doi.org/10.1016/i.cpa.2012.01.004

Hammersley, J. S., Myers, L. A., \& Shakespeare, C. (2008). Market reactions to the disclosure of internal control weaknesses and to the characteristics of those weaknesses under section 302 of the Sarbanes Oxley Act of 2002. Review of Accounting Studies, 13(1), 141-165, mar. https://doi.org/10.1007/s11142-007$\underline{9046-z}$

Hoi, C. K., Wu, Q., \& Zhang, H. (2019). Does social capital mitigate agency problems? Evidence from Chief Executive Officer (CEO) compensation. Journal of Financial Economics, 133(2), 498-519, ago. https://doi.org/10.1016/i.jineco.2019.02.009

Kassem, R., \& Hegazy, M. A. (2010). fraudulent financial reporting: do red flags really help? International Journal of Academic Research: Economics and Engineering, 4, dez.

Krambia-Kapardis, M., Christodoulou, C., \& Agathocleous, M. (2010). Neural networks: the panacea in fraud detection? Managerial Auditing Journal, 25(7), 659-678, 27 jul. https://doi.org/10.1108/02686901011061342

Lenard, M. J., Petruska, K. A., Alam, P., \& Yu, B. (2016). Internal control weaknesses and evidence of real activities manipulation. Advances in Accounting, 33, 47-58, jun. https://doi.org/10.1016/j.adiac.2016.04.008

Li, Y., Park, Y., \& Wynn, J. (2018). Investor reactions to restatements conditional on disclosure of internal control weaknesses. Journal of Applied Accounting Research, 19(3), 423-439, 10 set.

https://doi.org/10.1108/JAAR-10-2017-0107

Liu, X., \& Liu, X. (2017). CEO equity incentives and the remediation of material weaknesses in internal control. Journal of Business Finance \& Accounting, 28 jul. https://doi.org/10.1111/jbfa.12265

Lopes, I. M. O., Marques, V. A., \& Louzada, L. C. (2019). Deficiências dos controles internos das empresas listadas na [B3]. Revista Evidenciação Contábil \& Finanças, 7(3), 105-126, 2 set. https://doi.org/10.22478/ufpb.2318-1001.2019v7n3.41207

Omar, N., Johari, Z., Amirah, \& Smith, M. (2017). Predicting fraudulent financial reporting using artificial neural network. Journal of Financial Crime, 24(2), 362-387, 2 maio. https://doi.org/10.1108/JFC-11-20150061

Rae, K., Sands, J., \& Subramaniam, N. (2017). Associations among the five components within COSO internal control-integrated framework as the underpinning of quality corporate governance. Australasian Accounting, Business and Finance Journal, 11(1), 28-54. https://doi.org/10.14453/aabfj.v11i1.4

Rice, S. C., \& Weber, D. P. (2012). How effective is internal control reporting under SOX 404? Determinants of the (non-)disclosure of existing material weaknesses. Journal of Accounting Research, 50(3), 811-843, jun. https://doi.org/10.1111/j.1475-679X.2011.00434.x

Saldaña, J. (2013). The coding manual for qualitative researchers. 2nd. Los Angeles: Sage.

Su, L., Zhao, X. \& Zhou, G. (2014). Do customers respond to the disclosure of internal control weakness? Journal of Business Research, 67(7), 1508-1518, jul. https://doi.org/10.1016/j.jbusres.2013.06.009

Teixeira, S. A., \& Cunha, P. R. (2016). Índice de deficiências de controle interno: análise de empresas brasileiras listadas na BM\&FBOVESPA. Anais do $X$ Congresso ANPCONT, http://anpcont.org.br/pdf/2016/MFC327.pdf

Teixeira, S. A., \& Cunha, P. R. (2016a). Efeito moderador das deficiências do controle interno na relação 
entre seus determinantes e consequentes. Anais do XVI Congresso USP Controladoria e Contabilidade, São Paulo https://congressousp.fipecafi.org/anais/artigos162016/220.pdf

Wooldridge, J. (2011). Econometric analysis of cross section and panel data. 2nd. Cambridge: MITMassachussets Institute Technology, 2011.

Zakaria, K. M., Nawawi, A., \& Salin, A. S. A. P. (2016). Internal controls and fraud-empirical evidence from oil and gas company. Journal of Financial Crime, 23(4), 1154-1168, 3 out. https://doi.org/10.1108/JFC-04$\underline{2016-0021}$ 
Apêndice A - Estudos Empíricos Internacionais sobre Red Flags e Deficiências de Controle Interno Autor (Ano)

Título

Objetivo

Procedimentos

Principais resultados

Feroz, Kwon, The Efficacy of Red Flags in Predicting Fornecer aos reguladores informações

Pastena e Park the SEC's Targets: An Artificial Neural

(2000) Networks Approach.

violações.

metodológicos/Amostra

\section{Hegazy}

e Financial reporting fraud: Do red flags

Kassem (2010) really help?

Rice e Weber How Effective Is Internal Control

Reporting under SOX 404?
Determinants of the (Non-) Disclosure of

Existing Material Weaknesses.

Su; Zhao e Zhou

Do customers respond to the disclosure of internal control weakness?

\section{à divulgação de $\mathrm{DCl}$ pelas empresas.}

Determinar se red flags são úteis para auxiliar auditores externos a detectar fraudes em relatórios financeiros.

Examinar, por meio da identificação de Cl, a eficácia dos relatórios de Sarbanes Oxley SOX 404 .

Lenard et al Internal control weaknesses and (2016) evidence of real activities manipulation

akaria, Nawawi Internal Controls and Fraud - Empirical Identificar DCl e fraudes cometidas em e Salin (2016) se há relação entre os relatórios com $\mathrm{DCl}$ arquivados na SEC o nível de manipulação de atividades consequência delas. regressões

logísticas

veling presentes no balancete, aliados a red flags não financeiras (ex.: rotatividade

estatística descritiva. 93 entrevistados.

Estatística descritiva regressão. 488 empresas.

Estatística descritiva regressão.

observações.

de Chief Executive Officer, Chief Financial Officer e auditores).

A combinação de red flags específicas e red flags na Statement on Auditing Standards SAS 99 podem aumentar a capacidade dos auditores externos na detecção de fraudes.

Existe uma associação negativa entre a probabilidade de reporte de DCl, tamanho da empresa e a presença das Big4. Além disso, existe uma associação positiva entre reformulações de $\mathrm{DCl}$ e mudanças recentes do auditor e da administração.

descritiva regressão. 904 empresas.

indústrias de bens duráveis, com alta intensidade de pesquisa e desenvolvimento, ou sem correção subsequente dessas $\mathrm{DCl}$.

Identificaram uma queda no crescimento das vendas na indústria posterior a divulgação de $\mathrm{DCl}$, tal declínio é mais acentuado nas a manipulação real de atividades, os resultados sugerem que
empresas com DCl são propensas a utilizar de manipulação como meio de gerenciar resultados.

Estudo de caso, análise de documentos e entrevista. empresa.
Foram identificadas $\mathrm{DCl}$ (ex falta de supervisão em horas extras de pessoal e falta de monitoramento de pedidos de compra); bem como fraudes cometidas (ex. propinas sobre o pagamento de horas extras e criação de uma fatura fictícia). 
Apêndice B - Operacionalização das Variáveis Utilizadas Modelo

Sigla Descrição $\quad$ Fórmula

Variáveis Dependentes (Deficiências de Controles Internos)

DCl Deficiência dos Controles Internos Variável dummy que assume valor 1 quando reportou 1 ou mais DCl e 0 quando não.

QTDEDCI Quantidade de Deficiências de Controle Logaritmo natural do total de DCl reportadas por empresa/ano. Interno reportadas

Variáveis Independentes (Red Flags)

\begin{tabular}{|c|c|c|}
\hline IDVR & Índice de Dias de Vendas em Recebíveis & $\frac{\left(\text { Clientes }_{t}-\text { Vendas }_{t}\right)}{\left(\text { Clientes }_{t-1}-\operatorname{Vendas}_{t-1}\right)}$ \\
\hline IMB & Índice de Margem Bruta & $\frac{\left(\mathrm{LB}_{\mathrm{t}-1} \div \text { Vendas }_{\mathrm{t}-1}\right)}{\left(\mathrm{LB}_{\mathrm{t}} \div \text { Vendas }_{\mathrm{t}}\right)}$ \\
\hline IQA & Índice de Qualidade dos Ativos & $\left\{\frac{1-\left[\left(\mathrm{AC}_{\mathrm{t}}+\mathrm{Imob}_{\mathrm{t}}\right) \div \text { Ativo }_{\mathrm{t}}\right]}{1-\left[\left(\mathrm{AC}_{\mathrm{t}-1}+\mathrm{Imob}_{\mathrm{t}-1}\right) \div \mathrm{Ativo}_{\mathrm{t}-1}\right]}\right\}$ \\
\hline ICV & Índice de Crescimento de Vendas & $\left(\frac{\text { Vendas }_{\mathrm{t}}}{\text { Vendas }_{\mathrm{t}-1}}\right)$ \\
\hline ID & Índice de Depreciação & $\left\{\frac{\left[\text { Deprec }_{t-1} \div\left(\text { Deprec }_{t-1}+\operatorname{Imob}_{\mathrm{t}-1}\right)\right]}{\left[\text { Deprec }_{\mathrm{t}} \div\left(\text { Deprec }_{\mathrm{t}}+\operatorname{Imob}_{\mathrm{t}}\right)\right]}\right\}$ \\
\hline DVGA & Índice de Despesas de Vendas, Gerais e Adm. & $\frac{\left(\text { DespesasVGA }_{\mathrm{t}} \div \text { Vendas }_{\mathrm{t}}\right)}{\left(\text { DespesasVGA }_{\mathrm{t}-1} \div \text { Vendas }_{\mathrm{t}-1}\right)}$ \\
\hline IA & Índice de Alavancagem & $\left\{\frac{\left[\left(\text { DívidasL }_{\mathrm{t}}+\mathrm{PC}_{\mathrm{t}}\right) \div \text { Ativo }_{\mathrm{t}}\right]}{\left[\left(\text { DívidasL }_{\mathrm{t}-1}+\mathrm{PC}_{\mathrm{t}-1}\right) \div \mathrm{Ativo}_{\mathrm{t}-1}\right]}\right\}$ \\
\hline TATA & Total de Accruals por Total de Ativos & $\left\{\frac{\left(\Delta \mathrm{AC}_{\mathrm{t}}-\Delta \text { Caixa }_{\mathrm{t}}-\Delta \mathrm{PC}_{\mathrm{t}}-\Delta \text { DívidasLP }_{\mathrm{t}}-\Delta \mathrm{IRpg}_{\mathrm{t}}-\Delta \text { Deprec }_{\mathrm{t}}\right)}{\Delta \mathrm{tiv} O}\right\}$ \\
\hline IQL & Índice de Qualidade dos Lucros & $\left(\frac{\mathrm{FCO}_{\mathrm{t}}}{\mathrm{LL}_{\mathrm{t}}}\right)$ \\
\hline
\end{tabular}

Variáveis de Controle

\begin{tabular}{|c|c|c|}
\hline Tam & Tamanho & Logartimo natural do total de ativos. \\
\hline Idade & Idade & Logaritmo natural do total de anos de registro da firma. \\
\hline NM & Novo Mercado & $\begin{array}{l}\text { Variável dummy que assume valor } 1 \text { quando a empresa é listada no nível } \\
\text { NM de governança, } 0 \text { para os demais. }\end{array}$ \\
\hline RepObr & Republicação Obrigatória & $\begin{array}{l}\text { Variável dummy que assume valor } 1 \text { quando a empresa republicou, } 0 \\
\text { para os demais. }\end{array}$ \\
\hline SegEcon & Segmento Econômico & Variável dummy que assume valor 1 para o ano i, 0 para os demais. \\
\hline Ano & Ano & Variável dummy que assume valor 1 para o ano t, zero para os demais. \\
\hline \multicolumn{3}{|c|}{$\begin{array}{l}\text { Nota: DSRI - Índice de Dias de Vendas em Recebíveis; IMB - Índice de Margem Bruta; IQA — Índice de Qualidade dos Ativos; ICV } \\
\text { - Índice de Crescimento de Vendas; IDEPI — Índice de Depreciação; IDVGA - Índice de Despesas de Vendas Administrativas } \\
\text { Gerais; IA - Índice de Alavancagem; TATA - Total de Accruals para o Total de Ativos; t corresponde ao ano corrente e t-1 ao período } \\
\text { anterior; } \Delta \text { mede a variação; AC - Ativo Circulante; Deprec - Despesa com Depreciação e Amortização; DespesasVGA - Despesas } \\
\text { de Vendas, Gerais e Administrativas; DívidasLP - Empréstimos de Longo Prazo; Imob - Imobilizado; IRpg - Imposto de Renda a } \\
\text { pagar; LB - Lucro Bruto; PC - Passivo Circulante. }\end{array}$} \\
\hline
\end{tabular}




\section{NOTAS}

\section{AGRADECIMENTOS}

Os autores agradecem aos avaliadores do XIV ANPCONT e da Revista Contemporânea de Contabilidade pelas considerações e sugestões de melhoria.

\section{CONTRIBUIÇÃO DE AUTORIA}

Concepção e elaboração do manuscrito: C.V. Brandão, L.B. Mascarenhas, V.A. Marques

Coleta de dados: C.V. Brandão, L.B. Mascarenhas, V.C. Freitag

Análise de dados: C.V. Brandão, L.B. Mascarenhas, V.A. Marques

Discussão dos resultados: C.V. Brandão, L.B. Mascarenhas, V.A. Marques, V.C. Freitag

Revisão e aprovação: V.A. Marques, V.C. Freitag

\section{CONJUNTO DE DADOS DE PESQUISA}

Todo o conjunto de dados que dá suporte aos resultados deste estudo foi publicado no próprio artigo.

\section{FINANCIAMENTO}

Equipamentos, produtos ou recursos: Conselho Nacional de Desenvolvimento Científico e Tecnológico Processo 421583/2018-5. Bolsas: O presente trabalho foi realizado com apoio da Fundação de Amparo à Pesquisa e Inovação do Espírito Santo (FAPES). O presente trabalho foi realizado com apoio da Coordenação de Aperfeiçoamento de Pessoal de Nível Superior - Brasil (CAPES) - Código de Financiamento 001

\section{CONSENTIMENTO DE USO DE IMAGEM}

Não se aplica.

\section{APROVAÇÃO DE COMITÊ DE ÉTICA EM PESQUISA \\ Não se aplica.}

\section{CONFLITO DE INTERESSES}

Não se aplica.

\section{LICENÇA DE USO}

Os Direitos Autorais para artigos publicados neste periódico são do autor, com direitos de primeira publicação para a Revista. Em virtude de aparecerem nesta Revista de acesso público, os artigos são de uso gratuito, com atribuições próprias, em aplicações educacionais, de exercício profissional e para gestão pública. A Revista adotou a licença Creative Commons Atribuição 4.0 Internacional - CC BY NC ND. Esta licença permite acessar, baixar (download), copiar, imprimir, compartilhar, reutilizar e distribuir os artigos desde que com a citação da fonte, atribuindo os devidos créditos de autoria. Nesses casos, nenhuma permissão é necessária por parte dos autores ou dos editores. Autores têm autorização para assumir contratos adicionais separadamente, para distribuição não-exclusiva da versão do trabalho publicada nesta revista (ex.: publicar em repositório institucional ou um capítulo de livro).

\section{PUBLISHER}

Universidade Federal de Santa Catarina. Curso de Ciências Contábeis e Programa de Pós-graduação em Contabilidade. Publicação no Portal de Periódicos UFSC. As ideias expressadas neste artigo são de responsabilidade de seus autores, não representando, necessariamente, a opinião dos editores ou da universidade.

\section{EDITORES}

Carlos Eduardo Facin Lavarda e Suliani Rover

\section{HISTÓRICO}

Recebido em: 25/08/2020 - Revisado por pares em: 23/12/2020 - Reformulado em: 30/01/2021 Recomendado para publicação em: 29/03/2021 - Publicado em: 30/06/2021

*Uma versão prepint do artigo foi apresentado no XIV Congresso Anpcont, 2020. 